Article

\title{
Do Science, Technology, Engineering and Mathematics (STEM) Experimentation Outreach Programs Affect Attitudes towards Mathematics and Science? A Quasi-Experiment in Primary Education
}

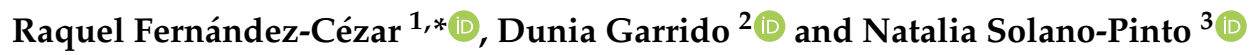 \\ 1 Mathematics Department, Faculty of Education of Toledo, Castilla La Mancha University, \\ 13001 Ciudad Real, Spain \\ 2 Psychology Department, Faculty of Health Sciences of Talavera, Castilla La Mancha University, \\ 13001 Ciudad Real, Spain; dunia.garrido@uclm.es \\ 3 Psychology Department, Faculty of Education of Toledo, Castilla La Mancha University, \\ 13001 Ciudad Real, Spain; natalia.solano@uclm.es \\ * Correspondence: raquel.fcezar@uclm.es; Tel.: +34-925-268-800 (ext. 4743)
}

Received: 29 July 2020; Accepted: 1 September 2020; Published: 3 September 2020

\begin{abstract}
Science, technology, engineering and mathematics (STEM) outreach programs have been widely studied in recent years considering their possible influence on future STEM career election aiming to counteract the observed decline in enrollment at university. Nonetheless, the presumed effect is not clear due to a lack of comparison with control groups. In order to fill this gap, a quasi-experimental design was adopted to analyze the effect of a STEM experimentation outreach program on 5th and 6th graders. The sample was composed by 453 students, (274 experimental group and 179 control group). The Auzmendi Scale of Attitude towards Mathematics Modified (ASMAm), and the attitude towards school science (ASSci), were used as instruments, and were administered before and after the intervention. The analysis was run with sex, type of school (state and state-funded schools), school environment (rural/urban), and teacher as potential factors. The results show that there is a program effect on the attitude towards mathematics, but not on the attitude towards school science. Regarding the factors, the program effect is associated neither with sex nor with rural/urban schools. However, the program had a more positive effect on the ASSci than on the ASMAm in the state schools, and is mediated by the teacher.
\end{abstract}

Keywords: STEM; attitude towards mathematics; attitude towards science; outreach program; quasi-experiment

\section{Introduction}

The current society is increasingly based on mathematics, science, technology, and information. Technological knowledge is becoming more specialized and most jobs are created around this technological development [1]. Nonetheless, the decline in enrollment in Science, Technology, Engineering, and Mathematics (STEM) careers continues [2,3]. Some actions are performed, such as fostering outreach programs from policy makers, among which we can find the STEM outreach programs involving scholars, researchers, teachers, and students at the pre-university level. To some extent, they are considered as a possible solution to counteract the actual decline in enrollment in STEM careers in the western world, particularly among girls [4-8]. As a second step, a measurement of the STEM outreach programs effect has become a necessity. Therefore, in recent years there has been a significant increase in the literature dealing with the presentation and evaluation of effects of outreach programs, 
remarking on their potential to foster STEM careers among pre-university students. Nonetheless, Sadler, Eilam, Bigger and Barry [9] recognized that their impact is not yet well understood due to a lack of deep analysis on which outreach programs to deliver, and to whom. In the realm of clarifying the STEM outreach programs' effectiveness, it should be added that knowing the variables to measure that impact, the possible factors that could affect that impact, and the adequate design to collect valuable data is crucial. These aspects, the types of programs to deliver, the variables to measure effectiveness and the experimental design, are focused on next.

\section{Literature Review}

In the reviewed literature, there is a wide variety of outreach programs, but all of them are driven by institutions which are external to the schools. Therefore, they offer participation outside the school environment as extracurricular activities. Among them, Siew Goh and Sulaiman [10] reported on a STEM outreach program involving STEM in an engineering design process with 10th graders, mostly aged about 16, from two rural schools in Malaysia. The action lasted for $10 \mathrm{~h}$, and researchers administered post questions. Their results showed an improvement in the students' attitudes and in their high-order thinking skills. Flash, Allen, Mack and Clement [11] reported on a program delivered through a library, the Big Orange STEM Saturday (BOSS), which connects secondary education students with experts in Tennessee (USA). They discussed the benefits of the work they did in stablishing communication between the school and the real world, but the paper does not include any empirical evidence. Although most of the effects of outreach programs have focused on participants, the work of Fitzallen and Brown [12] focused on volunteer engineering students delivering the outreach program in schools. They claimed benefits for these engineering students by reporting positive results regarding motivation and commitment, science communication skills and awareness of teaching and learning science from a case study in a regional university in Australia. Segarra, Natalizio, Falkenberg, Pulford and Holmes [13] revised the influence of including art in science outreach, concluding that it is positive for K-12 students and for the development of professional scientists. Porter [14] introduced a 3D-printable resources program driven to design laboratory tool kits with pre-university students. The author presented his own reflections on the fact that these kinds of programs provided effective ways to discover the technology and fundamental principles of laboratory analysis, without empirical evidence. Clarke, Sharma and Schiller [15] presented an outreach program with 3-h hands-on, physiology-based experiences addressed to students in a school in Nebraska (USA). The participants posed questions in the sessions, which were recorded. The analysis of these questions resulted in two categories: scientific and career-related content, including those related to day-to-day activities of a scientist and the volunteers' satisfaction with a scientific career. They concluded that this program, based on hands-on experiences, is effective in generating short-term interest in STEM content and careers. Another positive influence on the participants, particularly in younger students, was the outreach program presented by Fernández-Cézar, Pinto-Solano and Muñoz-Hernández [16], based on experimentation performed by university and research Spanish centers who visited the schools, dealing with 380 students from 6th Primary Education grade, 3rd Compulsory Secondary Education, and 1st Baccalaureate. The effect of STEM outreach activities of a different nature on students' motivation was offered in the work of Vennix, den Brok and Taconis [17], which analyzed a sample of 729 students from the USA and the Netherland involved in different contexts. These authors concluded that the nature of the activity and the context did influence the intrinsic motivation. Therefore, regarding the nature of the program, there is not conclusive information (i.e., including hands-on experiments or not), while the results of participants seem to be positive towards STEM subjects in all the cases.

Regarding the factors affecting the STEM outreach program effect, there are no references in the reviewed studies [9-17] to sex, school context or target participants. Nonetheless, all the referenced outreach programs were focused on pre-university students and had a more intense effect in younger students [16]. 
Since outreach programs are conceived as extracurricular activities, achievement is typically discarded as a measurable variable. Moreover, students' attitudes are more important, influencing student motivation to choose STEM careers than performance and achievement, as proved empirically by [2] Maltese and Tai. Therefore, the effect of life experience during participation in the program, and the possible effect on attitudes is considered. Several researchers refered to the role of past experiences in determining future STEM elections related to science [18,19], and mathematics [20,21]. All of them emphasized the influence of these past experiences on cognitive-affective variables (e.g., self-efficacy, attitudes, motivation, and beliefs). Since most of the STEM outreach programs aim to counteract the STEM decline at university level, the organizers search to estimate the influence of these programs in younger students as regards the affective domain through their attitude, which is assumed to be a predictor of future STEM elections. Considering the outreach program presented in this paper as an experience for students, the variable to be measured is the attitude, and provided that, in the Spanish curriculum of Primary Education, the STEM subjects are specifically mathematics and science, it is materialized as the attitude towards mathematics and the attitude towards science.

\subsection{Attitude towards Mathematics and Science}

The study of attitude started in the field of social psychology (Allport, 1935, cited in di Martino and Zan) [22] with the aim of predicting future elections or behaviors, like voter intention and consumer purchases. In addition, attitude was considered as modifiable traits [23] that can be considered as positive or negative in the sense that they can result in attraction or aversion [24] respecting the subject of the attitude.

Within education, attitude is a construct that has been linked to different conceptual models. In this work, we assumed the construct definition proposed by Gómez Chacón [25] as an evaluative behavioral predisposition that determines personal intentions and influences behavior, and that is composed of cognitive, affective, and behavioral components, in such a way that the attitude encompasses individual cognition and affect, and could influence future elections.

Students' attitudes are an important factor influencing student motivation to learn STEM subjects and pursue a STEM career [2]. In this respect, there has been wide research conducted about student attitude toward mathematics [26-28], and several reviews of the existing literature about attitude toward science [29-31]. In these reviews, in the two fields of mathematics and science, the existence of mathematic attitude or scientific attitude is recognized, on the one hand, and the attitude towards mathematics or towards science [32] on the other, with the latter being related more to affect. These attitudes towards mathematics and science are of interest for this research. Regarding instruments, in the aforementioned reviews, diverse instruments were used to measure the attitude. As realized by several researchers $[33,34]$ the time-information relationship is optimized by questionnaires. Nonetheless, regarding attitude towards mathematics and science, most of the questionnaires are missing psychometric properties, are not adapted to the current society, are too lengthy for young students, or need translation or context adaptation because they are generated for students in foreign countries, immersed in different societies [35,36]. Therefore, in this study, the questionnaire on attitude towards mathematics modified from Auzmendi [37], whose psychometric properties were reported by Fernández-Cézar et al. [38], was used to measure the attitude towards mathematics. As for the attitude towards science, the questionnaire used by Fernández-Cézar et al. [16], based on the Relevance of Science Education (ROSE) study, My Science Class section [39] was applied.

Regarding factors that could affect the attitude, the role of sex is controversial. On the one hand, Fernández-Cézar et al. [16,39] did not find any effect, while STEM enrollment figures do exhibit a different trend and support the more negative attitude towards STEM on girls [2]. The school or learning environment and its relation to outreach programs have been analyzed by Vennix et al. [17], who reported a positive effect on the students' motivation and attitude. In this respect, the school type, and the rural or urban environment as part of the learning environment are analyzed. 
With relation to the school type and the possible influence on the attitude towards mathematics or science, no literature was found to the best of our knowledge. Nonetheless, several studies with samples including students of different schools, in relation to the attitude towards mathematics, are found, without comparison among them. On the one hand, Ekowati et al. [40] dealt with two schools, a Directive Primary School and a Catholic Primary School in Kupang, Indonesia, analyzing how to teach students to care about the environment through a realistic approach through mathematics materials. They chose the two schools because teachers of the 1st grade used similar instructions not based in traditional use of mainstream books. The findings did not show any difference regarding the type of school. On the other hand, Appiah [41] conformed a sample of senior high school students from different schools, public and private, in Ghana. The findings suggested that the attitude towards mathematics in the participants is significantly and positively influenced by the school environment. However, in both studies, the conclusions pointed to teachers as the main protagonists of the school and learning environment.

Regarding the role on the attitude of teachers, Sebastián and Galagovsky [42] adopted a qualitative perspective to study the implicit beliefs of active teachers in the use of active methodologies in science teaching. They found that, sometimes, teachers perceive innovative proposals as a difficulty in acquiring theoretical scientific concepts for students, which constitutes an obstacle in the implementation of such proposals. Therefore, the authors concluded that it is important to take this into account in the teachers' own training. Along this line, some studies [43] went deeper into the impact of the trainers of future teachers in the master's degree course in teacher training, and found that students valued the management of activities which help to learn and reflect on the learning of mathematical knowledge more than the curricular design of the actions themselves. Emphasizing the importance of teachers and the management of innovative activities, Peiró-Signes, et al. [44] carried out a model based on qualitative comparative analysis (fsQCA) to determine which attitude components would decrease anxiety towards statistics in secondary school students. As a result, the authors affirmed that motivation and self-confidence are key components of attitude to reduce anxiety towards the subject and achieve a higher performance. Based on their findings, the authors stressed the importance of meaningful classroom activities by showing the usefulness of the content for real-world understanding.

\subsection{Experimental Design}

In the reviewed literature on the evaluation of STEM outreach programs [9-17], if there is any empirical measurement with data collection, the education experiment is not properly designed. Thus, it does not allow for contrasting the participation in the outreach program effect with a group under similar conditions, except for the lack of participation, because they only use a treatment or experimental group. In this line, Clarke et al. [15] and Fernández-Cézar et al. [16], who offered empirical evidence, did work with pre- and post-test analysis, but only for the treatment group. The conclusions on the effectiveness of STEM outreach programs, or the lack of it, is weakened because of the experimental design, which is a weak quasi-experiment [45]. The quasi-experimental design could be reinforced by including, among the participants, a treatment group, the experimental, and a control group, with pre- and post-test, in order to contrast the effectiveness of the STEM outreach program participation on the attitude towards mathematics and the attitude towards science.

Therefore, in this paper, the gap is going to be filled by determining the effectiveness of a STEM outreach program by measuring the attitude towards mathematics and school science in 5 th and 6 th graders under a quasi-experimental design. The following research questions are addressed:

1. Does a STEM experimentation outreach program have any effect on the attitude towards mathematics and towards science in 5th and 6th graders?

2. Can this possible effect of a STEM experimentation outreach program be affected by factors such as sex, school type, school environment or the teacher? 
The results show that this STEM outreach experimentation program had a remarkable effect on the attitude towards mathematics, and the attitude towards school science was not remarkable, providing a small effect size in both cases.

\section{Materials and Methods}

A quantitative, descriptive, correlational, and inferential methodology was used. This study was designed as a quasi-experiment with a pre-test and post-test, administered to an experimental and control group, with a non-probabilistic sampling.

\subsection{Participants}

The sample was composed by 453 pupils of schools which applied for participation in the STEM experimentation outreach program "To know the science today opens the doors of tomorrow" [16,46] in the 2017-2018 academic year. The schools participating were located in Castilla La Mancha, Spain, and amounted to seven, the majority $(n=5)$ being state schools (SS) and the other two being state-funded schools (SFS). The students were enrolled in the last two courses of Primary Education (PE), 5th and 6th graders, with ages from 9 to $12(10.50 \pm 1.11)$, with mathematics and science as STEM subjects in the Spanish curriculum. Inside the schools, the students were taught by 22 different teachers. Table 1 shows the sample composition for the experimental (EG) and control group (CG), taking into consideration the factors of sex, school environment (rural or urban), and school type (SS or SFS).

Table 1. Sample composition by sex and school context.

\begin{tabular}{ccccc}
\hline Group & $\boldsymbol{N}$ & Boys/Girls & Rural/Urban & SFS/SS \\
\hline EG & 274 & $144 / 130$ & $138 / 136$ & $72 / 202$ \\
CG & 179 & $89 / 90$ & $121 / 58$ & $58 / 121$ \\
\hline
\end{tabular}

\subsection{Instrument}

Although the instrument used by Zakayira [35] for the attitude towards mathematics was developed recently and exhibited adequate psychometric properties, it was proved with students older than the ones involved in the current study, and would need translation into Spanish for our purpose. In this study, we chose the instruments under the following criteria: originally written in Spanish, to avoid translation, and not lengthy, to avoid the possible saturation of the young students. Taking that into account, the current instrument was a questionnaire composed by the Auzmendi Scale of Attitude towards Mathematics Modified (ASMAm), whose factor analysis for a teacher sample was reported in Fernández-Cézar et al. [38], exhibiting just one factor. As the items composing the factor refer to anxiety, the smaller the score in this scale, the better the attitude towards mathematics. The questionnaire also included attitude towards school science, ASSci, validated for PE students [16]. In this case, the higher the score, the more positive the attitude towards school science.

In both instruments, the statement in each item was evaluated as a 5-points Likert scale, where 1 means totally disagree and 5 totally agree, with 3 meaning neutrality. The items 1, 5 and 7 in the ASMAm scale were reversed due to the wording. These scales showed a good internal consistency, measured through Cronbach alpha coefficient, resulting in $\alpha=0.743$ for the ASMAm, and $\alpha=0.804$ for ASSci.

\subsection{Procedure and Intervention}

Schools applied through the program web site www.nanomadrid.es for participation. The school participation consisted of receiving university and national research centers' researchers who performed experiments with children inside the school. The dates for the experiments' sessions were agreed between schools and researchers and placed in a timeline between January and March. The pre-test questionnaires were delivered to the schools to be administered two weeks before the researchers 
visit, and the post-test was administered one week after the experiments' sessions. A number code was assigned to each school and teacher, and the alphabetical order of students in each class list was assigned to the students. The applicant teachers or school principals delivered all the questionnaires back to the researchers. The intervention was carried out in a two-hour session in the school day, as described by Fernández-Cézar et al. [16]. In performing the experiment, the discovery and the scientific method were combined in the way shown in Figure 1.

Table 2 shows the items in the questionnaire.

Table 2. Instruments.

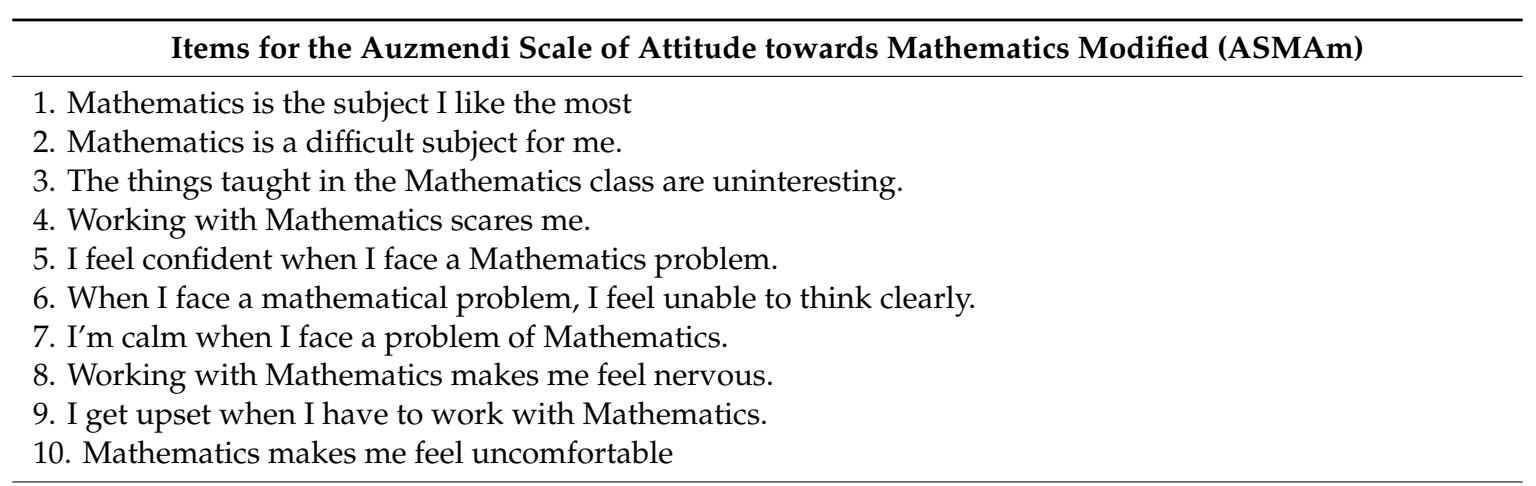

\section{Items for the Attitude towards School Science (ASSci)}

1. Science is one of the school subjects I like the most

2. School science is interesting

3. School science has opened my eyes to interesting jobs that I could choose when I'm an adult.

4. I like school science more than other subjects

5. I think that everybody should study science at school

6. The things that I learn in school science will help me in my future life

7. School science makes me like Nature more

8. School science has shown me the importance of science in our lifestyle

9. School science makes me pay attention to my health

10. When adult I would like to work as a laboratory researcher

11. When adult I would like to be a science teacher

12. I would like to have as much science as possible at school

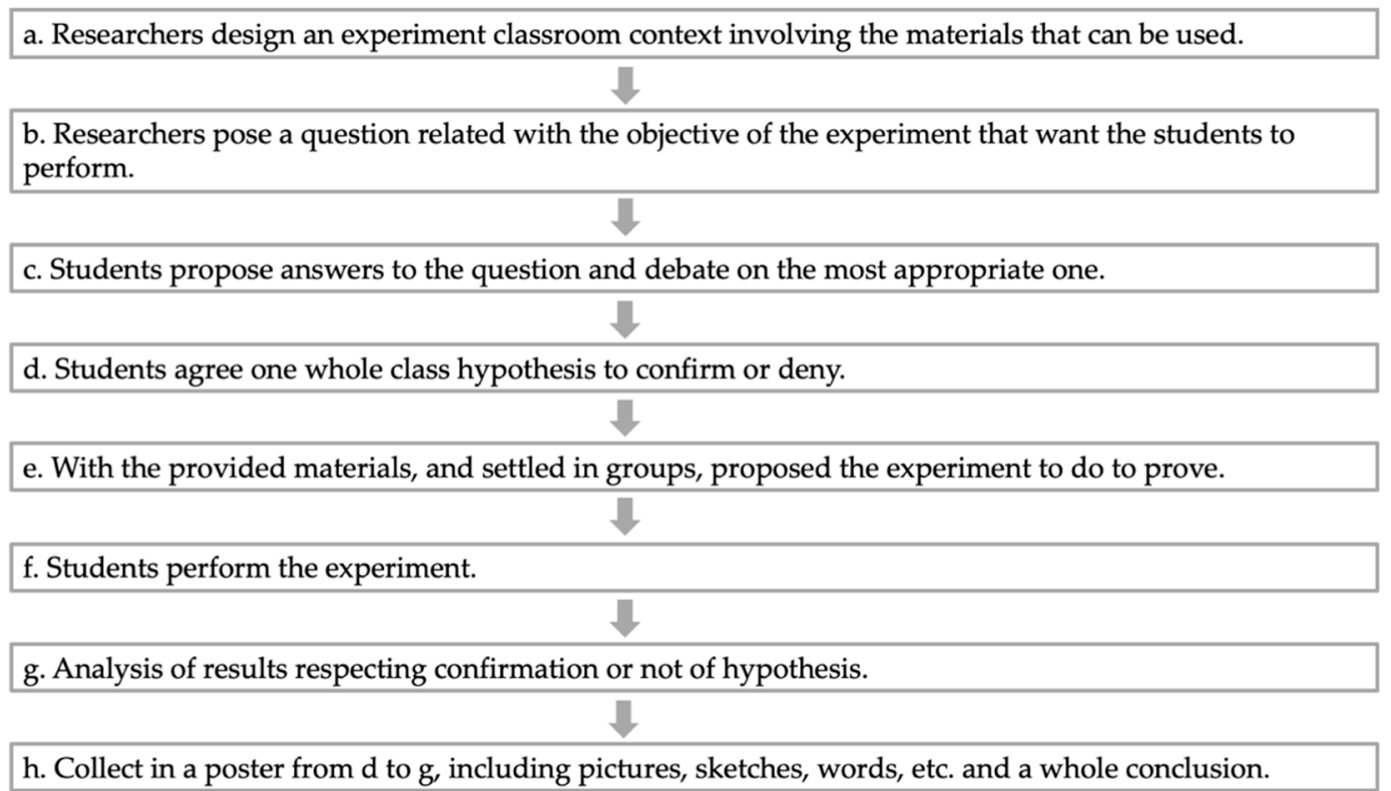

Figure 1. Intervention procedure. 
The school principals or teachers were asked before participation in the program. They were informed about the questionnaire administration, and the voluntary participation. All students and families gave their informed consent for inclusion before they participated in the study and knew that were free to give up the program at any time. The study was conducted in compliance with the Declaration of Helsinki.

\subsection{Data Analysis}

The quantitative analysis, descriptive and inferential, was performed with IBM Statistical Package for Social Sciences, SPSS, v24 (IBM, Armonk, NY, USA). The considered dependent variables were the attitude towards mathematics, ASMAm, and the attitude towards school science, ASSci, and the explored factors were sex, the type of school (state and state-funded), the school environment (rural or urban) and the role of the teacher. The effect of the STEM intervention with experimentation on the attitude towards mathematics and the attitude towards school science were measured by comparing the scores in the post-test with respect to the pre-test. Since the three numerical variables did not follow a normal distribution (K-S test for ASMAm, ASSci, IncASMAm, IncASSci; ps < 0.001), non-parametric tests were used.

In the analysis of the possible effect of the intervention comparing ASMAm and ASSci for students in the EG with those in the CG, a Wilcoxon test for related samples was used. To determine whether this effect could be associated with any of the four factors considered, the IncASMAm and IncASSci for the EG and the CG were compared through a U-Mann-Whitney test for sex, school type and school environment, and Kruskall-Wallis test for teacher. In all the tests, the $p$-values are compared with a significance level of 0.05 .

To reveal the intensity of the differences of the effect size, ES was appropriately calculated, depending on the test $[47,48]$, considering until 0.1 as small, between 0.1 and 0.3 as moderate, and above 0.5 as high.

\section{Results}

The general results for the attitude towards mathematics and the attitude towards school science in the EG and CG are shown in Figure 2.

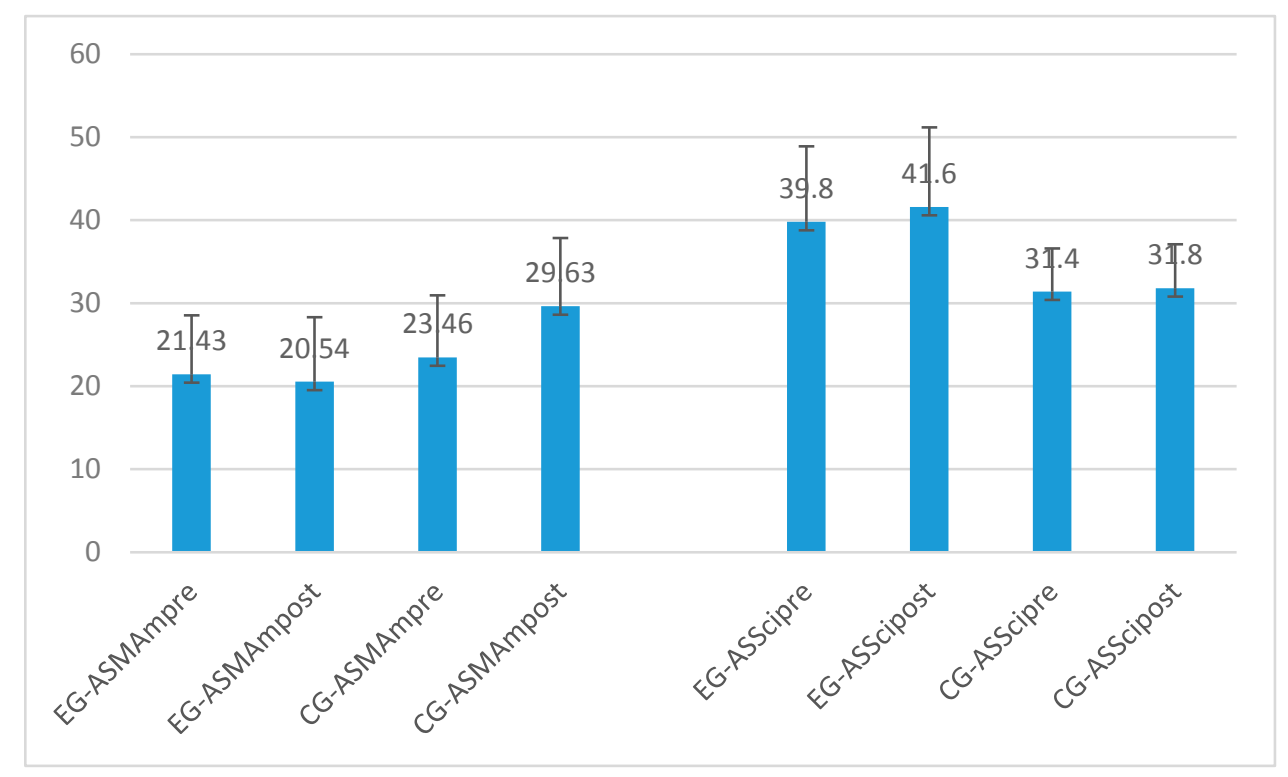

Figure 2. The attitude towards mathematics, ASMAm in the pre- and post-tests as well as the attitude towards school science, ASSci in pre- and post-tests are depicted for the experimental (EG), and control group (CG). $\mathrm{N}_{\mathrm{EG}}=274 ; \mathrm{N}_{\mathrm{CG}}=179$. ( $p=0.005$ for ASMAmpre and ASScipre in EG and $C G$ ). 
To get the difference in both variables in the experimental group (EG) and the control group (CG) for the pre- and post-tests, as indicated in the statistical analysis, the two-tail Wilcoxon test was used. For the attitude towards mathematics, the $p$-value was 0.428 for CG and 0.024 for EG, exhibiting no mean difference in the CG, while a significant difference for the EG was observed, which could be due to the experimentation performed during participation in the program. In the case of the attitude towards science, the same test delivers the following results: $p=0.012$ for CG, and $p=0.001$ for EG. In this case, both are in the rejection region, so the mean values are different no matter the participation, which could not only be assigned to the participation in the experimentation program, provided that students in the CG also exhibit that difference without participating. Therefore, it seems that this experimentation program had a remarkable effect on the attitude towards mathematics, but not on the attitude towards school science.

To go further in the knowledge of the effect of the experimentation program, the effect size was calculated for the cases where the differences were obtained, delivering the results shown in Table 3.

Table 3. ASMAm and ASSci, in experimental and control groups.

\begin{tabular}{ccc}
\hline Group & EG & CG \\
\hline ASMAm & 0.011 & - \\
ASSci & 0.013 & 0.004 \\
\hline
\end{tabular}

Note: the effect size was calculated as $2 \mathrm{xd} /(\mathrm{n}+1)$

Regarding the attitude towards mathematics, the intensity of the difference lightened by the effect size is small [48] and assigned to the participation in the experimentation program. In the case of the attitude towards school science, although in both groups the mean differences are significant, the effect size for the experimental group is bigger, which means that the participation in the experimentation program has an effect in this group, among other factors which were not controlled.

\section{Factors: Sex, School Type, School Environment and Teacher}

The descriptive values' mean and standard deviation, for the attitude towards mathematics and the attitude towards school science, are shown in Table 4 for boys and girls in the EG and CG.

Table 4. Mean, $\mathrm{M}$, and standard deviation, SD, of attitude towards mathematics and attitude towards school science for boys $(N=233)$ and girls $(N=220)$ in the experimental and control group. The increment for each is shown in the third column, IncASMAm and IncASSci. ( $N=274$ for EG; $N=179$ for $C G)$.

\begin{tabular}{cccccccc}
\hline Group & $\boldsymbol{N}$ & ASMAm Pre M & SD & ASMAm Post M & SD & IncASMAm M & SD \\
\hline \multirow{2}{*}{ EG } & Boy $=144$ & 20.21 & 7.13 & 19.18 & 7.61 & -1.02 & 6.45 \\
& Girl $=130$ & 22.27 & 7.20 & 21.36 & 7.69 & -0.91 & 5.46 \\
\hline \multirow{2}{*}{ CG } & Boy $=89$ & 22.65 & 7.03 & 21.45 & 8.59 & -1.20 & 6.40 \\
& Girl $=90$ & 23.88 & 7.21 & 27.86 & 9.76 & 4.03 & 9.85 \\
\hline \multirow{2}{*}{ Group } & $\boldsymbol{N}$ & ASSci Pre & SD & ASSci Post & SD & IncASSci & SD \\
\hline \multirow{2}{*}{ EG } & Boy $=144$ & 29.83 & 6.97 & 36.98 & 9.32 & 7.15 & 9.33 \\
& Girl $=130$ & 46.10 & 9.51 & 49.89 & 7.08 & 3.79 & 6.43 \\
\hline \multirow{2}{*}{ CG } & Boy $=89$ & 31.04 & 4.81 & 32.26 & 5.83 & 1.22 & 4.33 \\
& Girl $=90$ & 31.70 & 5.41 & 31.56 & 4.87 & -0.14 & 0.54 \\
\hline
\end{tabular}

To test whether participation in the experimentation program affects children in a different way depending on their sex, the possible association of the increment for attitude as well as attitude towards school science with this factor was analyzed. The results offered, for IncASMAm, a $p$-value $=0.142$ for the CG, and $p=0.807$ for the EG, indicating that the effect on the attitude towards mathematics of the participation in the program affects girls and boys evenly. On the other hand, the results for IncASSci exhibited a $p$-value $=0.002$ in the CG, and a $p$-value $=0.066$ in the EG. Since the IncASSci is significantly 
different for boys and girls in the CG, where the intervention did not take place, there is not interference at all of both factors. Therefore, neither the attitude towards mathematics nor the attitude towards school science in the EG show any association with sex, which implies that the participation in the experimentation program produced similar effects for both boys and girls.

Table 5 shows the mean and standard deviation for the attitude towards mathematics and the attitude towards school science, considering the school type (i.e., SS and SFS).

Table 5. Mean, M, and standard deviation, SD, of attitude towards mathematics and attitude towards school science for state-funded schools (SFS) and state schools (SS) in the experimental and control group. The increment for each is shown in the third column, IncASMAm and IncASSci. ( $N=274$ for EG; $N=179$ for $C G)$.

\begin{tabular}{|c|c|c|c|c|c|c|c|}
\hline Group & $\begin{array}{c}N \\
\text { SFS }=130 \\
\text { SS }=323\end{array}$ & ASMAm Pre M & SD & ASMAm Post M & SD & IncASMAm M & SD \\
\hline \multirow{2}{*}{ EG } & $\mathrm{SFS}=72$ & 20.57 & 6.31 & 19.86 & 6.52 & -0.71 & 5.94 \\
\hline & $S S=202$ & 21.50 & 7.51 & 20.44 & 8.09 & -1.05 & 6.30 \\
\hline \multirow{3}{*}{ CG } & $\mathrm{SFS}=58$ & 24.89 & 6.06 & 28.20 & 9.22 & 3.31 & 8.45 \\
\hline & $\mathrm{SS}=121$ & 22.49 & 7.51 & 21.39 & 9.58 & -1.10 & 7.33 \\
\hline & & ASSci Pre & SD & ASSci Post & SD & IncASSci & SD \\
\hline \multirow{2}{*}{ EG } & $\mathrm{SFS}=72$ & 36.22 & 7.14 & 38.18 & 8.81 & 1.96 & 1.98 \\
\hline & $S S=202$ & 36.22 & 7.44 & 38.63 & 7.70 & 2.41 & 1.13 \\
\hline \multirow{2}{*}{ CG } & $\mathrm{SFS}=58$ & 30.02 & 5.81 & 30.84 & 5.37 & 0.82 & 1.49 \\
\hline & $\mathrm{SS}=121$ & 32.02 & 4.67 & 32.39 & 5.27 & 0.37 & 1.07 \\
\hline
\end{tabular}

In order to discover whether the participation in the program could have a different effectiveness in students regarding the type of school, state-funded or state school, the possible association of the increment with the attitude towards mathematics as well as of attitude towards school science was analyzed in the EG, and compared with those in the CG. The results offered, for IncASMAm, a $p$-value $=0.021$ for the CG, and $p=0.992$ for the EG. With respect to the IncASSci, there was a $p$-value $=0.288$ in the CG, and a $p$-value $<0.000$ in the EG. This means that the participation in the experimentation program influenced the attitude towards mathematics in a similar manner in students attending both types of schools, while the attitude towards science is affected in a different way regarding the type of school. Despite the statistical significance, the ES for this association is 0.02 , which is small.

The third factor, which was analyzed in relation to the effectiveness of the program regarding whether participation in the program could have a different effectiveness in students, is the school setting, whether rural or urban. The results are depicted in Table 6. The possible association of the increment of attitude towards mathematics, as well as attitude towards school science, was analyzed in the EG and the CG. The results revealed, for IncASMAm, a $p$-value $=0.021$ for the CG, and $p$-value $=0.481$ for the EG. With respect to the IncASSci, a $p$-value $=0.288$ in the CG, and a $p$-value $=0.653$ in the EG. This means that the participation in the experimentation program had an impact on the students' attitude towards mathematics and their attitude towards school science in a similar way, regardless the urban or rural location of the school.

The fourth factor analyzed in this work is the teacher effect. In all the participant schools, the students were directed by 22 different teachers. For the study of the possible influence of the teacher on the attitude towards mathematics and the attitude towards school science, the association of this factor with the IncASMAm and IncASSci was measured by a two-tail Kruskal-Wallis test. In the EG, the $p$-value was 0.257 for IncASMAm, while the $p$-value was 0.018 for the CG. In the case of IncASSci, the $p$-value was 0.032 for students in CG, and $p$-value $=0.01$ in the EG. Therefore, participation in the program does not have a different effect on attitude towards mathematics in terms of teacher, 
while there is a different effect depending on the teacher for the attitude towards school science. Nonetheless, the size effect for IncASSci $\left(\mathrm{ES}_{\mathrm{V}-\mathrm{Cramer}}=0.08\right)$ is small [47].

Table 6. Mean, $\mathrm{M}$, and standard deviation, SD, of attitude towards mathematics and attitude towards school science for schools in rural $(N=259)$ and urban settings $(N=194)$, in the experimental and control group. The increment for each is shown in the third column, IncASMAm and IncASSci. ( $N=274$ for $\mathrm{EG} ; \mathrm{N}=179$ for $\mathrm{CG}$ ).

\begin{tabular}{cccccccc}
\hline Group & $\boldsymbol{N}$ & ASMAm Pre M & SD & ASMAm Post M & SD & IncASMAm M & SD \\
\hline \multirow{2}{*}{ EG } & Rural = 138 & 22.07 & 7.46 & 21.13 & 7.78 & -0.94 & 7.19 \\
& Urban $=136$ & 20.62 & 6.99 & 19.64 & 7.62 & -0.98 & 5.32 \\
\hline \multirow{2}{*}{ CG } & Rural = 121 & 22.49 & 7.51 & 21.39 & 9.58 & -1.10 & 7.33 \\
& Urban $=58$ & 24.89 & 6.06 & 28.20 & 9.22 & -3.31 & 8.45 \\
\hline \multirow{2}{*}{ Group } & $\boldsymbol{N}$ & ASSci Pre & SD & ASSci Post & SD & IncASSci & SD \\
\hline \multirow{2}{*}{ EG } & Rural = 138 & 38.37 & 7.36 & 40.16 & 9.72 & 0.98 & 4.80 \\
& Urban = 136 & 38.62 & 9.15 & 40.53 & 9.29 & 0.73 & 3.91 \\
\hline \multirow{2}{*}{ CG } & Rural = 121 & 32.01 & 4.67 & 32.39 & 5.27 & 0.32 & 4.71 \\
& Urban $=58$ & 30.02 & 4.82 & 30.84 & 5.33 & 1.20 & 4.49 \\
\hline
\end{tabular}

\section{Discussion}

The present paper has posed two research questions: Does a STEM outreach experimentation program have any effect on the attitude towards mathematics and towards science in 5th and 6th graders? Can this possible effect of a STEM experimentation outreach program be affected by factors such as sex, school type, school environment or the teacher?

To answer them, a quasi-experiment was designed, with 453 students composing the non-probabilistic sample. A pre- and post-test were administered to students in the experimental $(N=274)$ and control group $(N=179)$. The effect of a STEM outreach program on the attitude towards mathematics and the attitude towards school science were measured by the increment variable.

The first question is answered to an extent, provided that the results show that this STEM outreach program based on experimentation exerts and improvement in the attitude towards mathematics, given that it is less negative. Besides this, the attitude towards school science becomes more positive. However, both effects are small. Authors did not find any comparable studies, due to the lack of quasi-experimental designs similar to the one presented here. In the reviewed literature, quasi-experiments with an experimental and control group, with pre- and post-attitude measurements, are missing. Nonetheless, there were some strange variables that could not be controlled by researchers because the school groups were the natural ones, previously composed to participate in the program.

Assuming this lack of possible direct comparisons, regarding the nature of the activities in the outreach program, the found decrease in the attitude towards mathematics, which means a decrease in the anxiety, and an increase in the attitude towards school science, are all positive results. Therefore, this program has a positive effect on the attitude towards mathematics and science. Aligned with it are the positive findings on the interest in a scientific career reported by Clarke et al. [15] in their empirical study with physiology hands-on activities, the increase in social STEM attitude reported by Vennix et al. [17], and the increase in the attitude towards school science shown by Fernández-Cézar et al. [16]. The results of this kind of program on the attitude towards mathematics are not easily found in the literature, as far as we know. Nonetheless, our results are in line with several works in the field. For instance, Guzey, Harwell and Moore [32] described a positive impact of a STEM education program on attitude toward science and mathematics in middle school students. Additionally, Guzey, Ring-Whalen, Harwell, and Peralta [49] found a positive attitude toward STEM after taking part in the design of an engineering curriculum. Thus, it seems that different programs might have a positive influence on student attitude toward mathematics and science. 
Regarding the four factors analyzed touching this STEM program, firstly it is found that the program influenced neither the attitude towards mathematics nor the attitude towards school science differently for girls and boys. Although similar studies analyzing sex association with the effect of STEM outreach programs on attitude towards mathematics and science are not found, the findings on the role of sex on attitudes are controversial. Fernández-Cézar et al. [16] found a marginally significant positive effect on high school boys' attitude by analyzing an experimentation outreach program, while in younger students, Fernández-Cézar and Solano-Pinto [46] did not find any difference. On the other hand, there is a general belief, supported by enrollment figures in STEM careers, that girls are less inclined towards this kind of study. Therefore, more careful designs should be performed in the analysis of the effect of STEM experimentation outreach programs in order to clarify this association.

Secondly, the STEM program did not affect the students' attitude towards mathematics differently for different schools, SFS and SS, while it affects the attitude towards school science in a different manner. Even in that case, the effect size is small. These null effects of the school type on the attitude towards mathematics are aligned with the results of previous works [40,41], although the type of school was not particularly scrutinized. Unfortunately, no works comparing the effect on the attitude towards school science were found. This reinforces the importance of our work, which shows that the type of school has an influence on the attitude towards school science, being more positive after participation in STEM experimentation outreach program in state schools.

Thirdly, the STEM program effect on attitude towards mathematics and science is not significant for rural or urban settings. It contrasted with what was found by Fernández-Cézar et al. [16], who observed more positive attitude in students attending rural schools, although with a weaker quasi-experimental design.

Finally, the last factor required to completely answer research question 2 is the teacher. The participation in the experimentation STEM program does not have a different effect in terms of the teacher on the attitude towards mathematics, while it has a different effect depending on the teacher in the attitude towards school science. This aspect is important because, as other studies point out [42], the positive teacher belief in the benefits of innovative programs that foster significant learning is fundamental in order to include such programs in the curricular programming of science education, and not consisting only on a set of isolated activities. On the other hand, we must point out that the effect of this study, although significant, is small, perhaps because the teacher attitude is very deep-rooted, or because the carried-out experiments did not succeed in fostering an internal reflection in the teacher, which is an essential aspect in the constant learning process of the teacher himself [44]. In any case, the active and fundamental role of teachers in the student learning process is emphasized, as it is by other authors $[44,50]$.

\section{Conclusions}

To conclude, this paper partially fills the detected gap in the previous literature on the effect of STEM experimentation outreach programs on the attitude towards mathematics and the attitude towards school science because of its stronger design: a quasi-experiment with experimental and control group, and pre- and post-tests. In this respect, the results showed that there is a program effect on the attitude towards mathematics, and not that remarkable an effect on the attitude towards school science. The strange variables that are not considered in the study are not controlled because the groups were the natural ones in the schools. The groups were constituted previously to participation in the program, without any possible influence from the researchers. Among these strange variables, there could be the fact that EG and CG do not have similar attitude levels in the pretest, which could be considered as another covariate. The analysis of the possible covariates, sex, type of school (state and state funded schools), school environment (rural/urban), and teacher, reveals that the program effect is associated neither with sex nor with rural/urban schools. However, this program has a more positive effect on the ASSci than on the ASMAm in the state schools, an aspect that we could not contrast due to the lack of literature in this respect, which reinforces the importance of this finding. The last factor, the teacher, acts as a mediator of the program effect. Therefore, it is important to point out that 
with a short intervention, attitudes can be changed, but the change needs to be consolidated with the teacher's daily work.

These findings have been obtained by a multiple bivariate analysis, while there is another possibility for the data treatment: to perform a multivariable analysis with factors and attitude towards mathematics and science. The different data treatments may cause different results. Although we do not expect significant differences, this could be contrasted in a new study.

The study contributes to increasing the scarce research on the effects of STEM experimentation outreach programs on the attitude towards mathematics and science, and the factors that could be associated with that effect. However, it has several limitations. On the one hand, the sampling is non-probabilistic, which limits the generalizability of the results. On the other hand, this is a transversal study with Primary Education students whose future career elections are not recorded. Therefore, the actual influence of the STEM program on the increase in STEM vocations is yet to be determined.

Author Contributions: Conceptualization, R.F.-C., D.G. and N.S.-P.; methodology, R.F.-C., D.G. and N.S.-P.; formal analysis, R.F.-C., D.G. and N.S.-P.; investigation, R.F.-C., D.G. and N.S.-P.; writing-original draft preparation, R.F.-C., D.G. and N.S.-P.; writing-review and editing, R.F.-C., D.G. and N.S.-P.; project administration, R.F.-C. and N.S.-P.; funding acquisition, R.F.-C. and N.S.-P. All authors have read and agreed to the published version of the manuscript.

Funding: This research was funded by Spanish Foundation of Science and Technology, FECYT, grant number FCT-16-10952, and Castilla La Mancha University, grant number 2019-GRIN-27083.

Acknowledgments: We acknowledge the teachers, pupils and families voluntarily participating in the study, as well as the researchers making possible the "To know the science today opens doors of tomorrow project", specially to Pilar Amo.

Conflicts of Interest: The authors declare no conflict of interest.

\section{References}

1. OECD. Encouraging Student Interest in Science and Technology Studies; Policy Report; OECD Global Science Forum: Paris, France, 2008.

2. Maltese, A.V.; Tai, R.H. Pipeline persistence: Examining the association of educational experiences with earned degrees in STEM among U.S. students. Sci. Educ. 2011, 95, 877-907. [CrossRef]

3. Vázquez-Alonso, A.; Manassero-Mas, M.A. El descenso de las actitudes en la educación obligatoria. Ciênc. Educ. 2011, 17, 249-268. [CrossRef]

4. Manzano, A.; de Pro Bueno, A. Algunos datos sobre la visión de los niños y de las niñas sobre las ciencias y del trabajo científico. Rev. Género Igualdad 2018, 18-31. [CrossRef]

5. Patall, E.; Steingut, R.; Freeman, J.; Pituch, K.; Vasquez, A. Gender disparities in students' motivational experiences in high school science classrooms. Sci. Educ. 2018, 102, 951-977. [CrossRef]

6. Lytle, A.; Shin, J.E. Incremental Beliefs, STEM Efficacy and STEM Interest Among First-Year Undergraduate Students. J. Sci. Educ. Technol. 2020, 29, 272-281. [CrossRef]

7. Lin, T.; Tsai, C. Differentiating the Sources of Taiwanese High School Students' Multidimensional Science Learning Self-Efficacy: An Examination of Gender Differences. Res. Sci. Educ. 2018, 48, 575-596. [CrossRef]

8. Michell, D.; Szabo, C.; Falkner, K.; Szorenyi, A. Towards a socio-ecological framework to address gender inequity in computer science. Comput. Educ. 2018, 126, 324-333. [CrossRef]

9. Sadler, K.; Eilam, E.; Bigger, S.W.; Barry, F. University-led STEM outreach programs: Purposes, impacts, stakeholder needs and institutional support at nine Australian universities. Stud. High. Educ. 2018, 43, 586-599. [CrossRef]

10. Siew, N.M.; Goh, H.; Sulaiman, F. Integrating STEM in an engineering design process: The learning experience of rural secondary school students in an outreach challenge program. J. Balt. Sci. Educ. 2016, 15, 477.

11. Flash, K.; Allen, M.; Mack, T.; Clement, K. STEM bridges: Evolution of an academic library STEM outreach program. J. Libr. Adm. 2017, 57, 879-890. [CrossRef]

12. Fitzallen, N.; Brown, N.R. Outcomes for engineering students delivering a STEM education and outreach programme. Eur. J. Eng. Educ. 2017, 42, 632-643. [CrossRef] 
13. Segarra, V.A.; Natalizio, B.; Falkenberg, C.V.; Pulford, S.; Holmes, R.M. STEAM: Using the arts to train well-rounded and creative scientists. J. Microbiol. Biol. Educ. 2018, 19. [CrossRef] [PubMed]

14. Porter, L. 3D Printable Resources for Engaging STEM Students in Laboratory Learning Activities and Outreach Programs: Inexpensive and User-Friendly Instrument Kits for Educators. MRS Adv. 2018, 3, 2937-2942. [CrossRef]

15. Clarke, M.A.; Sharma, N.M.; Schiller, A.M. An outreach program with hands-on, physiology-based exercises generates questions about STEM career expectations. Adv. Physiol. Educ. 2019, 43, 175-179. [CrossRef]

16. Fernández-Cézar, R.; Pinto-Solano, N.; Muñoz-Hernández, M. Do experimentation outreach programs improve the attitudes towards school science? Rev. Educ. 2018, 381, 285-307. [CrossRef]

17. Vennix, J.; den Brok, P.; Taconis, R. Do outreach activities in secondary STEM education motivate students and improve their attitudes towards STEM? Int. J. Sci. Educ. 2018, 40, 1263-1283. [CrossRef]

18. Yuruk, N. The predictors of pre-service elementary teachers' anxiety about teaching science. J. Balt. Sci. Educ. 2011, 10, 17-26.

19. Avery, L.M.; Meyer, D.Z. Teaching science as science is practiced: Opportunities and limits for enhancing preservice elementary teachers' self-efficacy for science and science teaching. Sch. Sci. Math. 2012, 112, 395-409. [CrossRef]

20. Harari, R.R.; Vukovic, R.K.; Bailey, S.P. Mathematics anxiety in young children: An exploratory study. J. Exp. Educ. 2013, 81, 538-555. [CrossRef]

21. Thiel, O.; Jenssen, L. Affective-motivational aspects of early childhood teacher students' knowledge about mathematics. Eur. Early Child. Educ. Res. J. 2018, 26, 512-534. [CrossRef]

22. Di Martino, P.; Zan, R. Me and maths: Towards a definition of attitude grounded on students' narratives. J. Math. Teach. Educ. 2010, 13, 27-48. [CrossRef]

23. Heckman, J.; Stixrud, J.; Urzua, S. The effects of cognitive and non- cognitive abilities on labor market outcomes and social behavior. J. Labor Econ. 2006, 24, 411-482. [CrossRef]

24. Eiser, J.R. Psicología Social. Actitudes, Cognición y Conducta; Pirámide: Madrid, Spain, 1989.

25. Gómez Chacón, I.M. Matemática Emocional. Los Afectos en el Aprendizaje Matemático; Narcea: Madrid, Spain, 2000.

26. McLeod, D.B. Research on affect and mathematics learning in the JRME: 1970 to the present. J. Res. Math. Educ. 1994, 24, 637-647. [CrossRef]

27. Ma, X.; Kishor, N. Assessing the relationship between attitude toward mathematics and achievement in mathematics: A meta-analysis. J. Res. Math. Educ. 1997, 28, 27-47. [CrossRef]

28. Zan, R.; Brown, L.; Evans, J.; Hannula, M.S. Affect in mathematics education: An introduction. Educ. Stud. Math. 2006, 63, 113-121. [CrossRef]

29. Osborne, J.; Simon, S.; Collins, S. Attitudes towards science: A review of the literature and its implications. Int. J. Sci. Educ. 2003, 25, 1049-1079. [CrossRef]

30. Mellado, V.; Blanco, L.J.; Borrachero, A.B.; Cárdenas, J.A. Las Emociones en la Enseñanza y el Aprendizaje de las Ciencias y las Matemáticas; DEPROFE: Badajoz, Spain, 2013.

31. Potvin, P.; Hasni, A. Interest, motivation and attitude towards science and technology at K-12 levels: A systematic review of 12 years of educational research. Stud. Sci. Educ. 2014, 50, 85-129. [CrossRef]

32. Guzey, S.S.; Harwell, M.; Moore, T. Development of an instrument to assess attitudes toward science, technology, engineering, and mathematics (STEM). Sch. Sci. Math. 2014, 114, 271-279. [CrossRef]

33. Vázquez Alonso, Á.; Acevedo Díaz, J.A.; Manassero Mas, M.A.; Acevedo Romero, P. Actitudes del alumnado sobre ciencia, tecnología y sociedad, evaluadas con un modelo de respuesta múltiple. Rev. Electrón. Investig. Educ. 2006, 8, 1-37.

34. Kennedy, J.; Quinn, F.; Taylor, N. The school science attitude survey: A new instrument for measuring attitudes towards school science. Int. J. Res. Meth. Educ. 2016, 39, 422-445. [CrossRef]

35. Zakariya, Y.F. Development of attitudes towards mathematics scale (ATMS) using Nigerian data-Factor analysis as a determinant of attitude subcategories. Int. J. Prog. Educ. 2017, 13, 74-84.

36. Zakariya, Y.F. Development of mathematics anxiety scale: Factor analysis as a determinant of subcategories. J. Pedag. Res. 2018, 2, 135-144.

37. Auzmendi, E. Las Actitudes Hacia la Matemática-Estadística en las Enseñanzas Medias y Universitaria. Características y Medición; Mensajero: Bilbao, Spain, 1992. 
38. Cézar, R.F.; Pinto, N.S.; Rizzo, K.; Camino, A.G.; Iglesias, L.M.; Espinosa, A. Las actitudes hacia las matemáticas en estudiantes y maestros de educación infantil y primaria: Revisión de la adecuación de una escala para su medida. Rev. Iberoam. Cienc. Tecnol. Soc. 2016, 11, 227-238.

39. Schreiner, C.; Sjøberg, S. Showing the seeds of ROSE. Background, Rationale, Questionnaire Development and Data Collection for ROSE (The Relevance of Science Education)—A comparative study of students' views of science and science education. Acta Didact. 2004, 4, 66-67, 90. Available online: https://www. roseproject.no/key-documents/key-docs/ad0404-sowing-rose.pdf (accessed on 27 July 2020).

40. Ekowati, C. The Development of Thematic Mathematics Book Based on Environment with a Realistic Approach to Implant the Attitude of Caring about Environment at Students of Elementary School Grade One in Kupang. Int. J. High. Educ. 2017, 6, 112-121. [CrossRef]

41. Appiah, D. Senior High School Students' Attitude towards Mathematics and Perception of Their Mathematics Classroom Learning Environment. Ph.D. Thesis, University of Education, Winneba, Kumasi, Ghana, 2016. Available online: http://ir.uew.edu.gh/xmlui/handle/123456789/641 (accessed on 25 July 2020).

42. Sebastián, M.; Galagovsky, L. Enseñanza en contexto: La importancia de revelar obstáculos implícitos en docentes. Enseñanza de las Ciencias 2020, 38, 45-64. [CrossRef]

43. Rojas, F.; Deulofeu, J. El formador de profesores de matemática: Un análisis de las percepciones de sus prácticas instruccionales desde la tensión estudiante-formador. Enseñanza de las Ciencias 2015, 33, 47-71. [CrossRef]

44. Peiró-Signes, Á.; Trull, Ó.; Segarra-Oña, M.; García-Díaz, J.C. Attitudes Towards Statistics in Secondary Education: Findings from fsQCA. Mathematics 2020, 8, 804. [CrossRef]

45. Campbell, D.T.; Stanley, J.C. Experimental and Quasi-Experimental Designs for Research; Ravenio Books: Cambridge, UK, 2015.

46. Fernández-Cézar, R.; Solano-Pinto, N. Attitude towards school science in primary education in Spain. REDIE. Rev. Elect. Inv. Ed. 2017, 19, 112-123. [CrossRef]

47. Manzano-Arrondo, V. Sobre la Acotación de Efectos y la Existencia de Relación. Available online: http: //asignatura.us.es/dadpsico/apuntes/efectos.pdf (accessed on 24 July 2020).

48. Cohen, J. Statistical Power Analysis for the Behavioral Sciences; Routledge: New York, NY, USA, 2013.

49. Guzey, S.S.; Ring-Whalen, E.; Harwell, M.; Peralta, Y. LifeSTEM: A study of life science learning through engineering design. Int. J. Sci. Math. Educ. 2017, 17, 23-42. [CrossRef]

50. Hattie, J. Visible Learning for Teachers: Maximizing Impact on Learning; Routledge: New York, NY, USA, 2012. 